\title{
Relationship Between Reorganization Turnaround Strategy And Performance Of Small And Medium Enterprises In Kenya
}

\author{
Antony Sije*, Dr. Jane Omwenga, and Dr. Mike Iravo \\ Jomo Kenyatta University of Agriculture and Technology
}

\begin{abstract}
The main objective of this study was to determine the relationship between reorganization turnaround strategy and performance of small and medium enterprises in Kenya. The total target population was 8604. A total of 375 respondents were used as the sample size for the study. Descriptive survey design and correlational research design were used in this study. This study tested the null hypotheses that reorganization turnaround strategy has no relationship with the performance of SMEs in Kenya. The study found that there was positive and significant relationship between reorganization turnaround strategy and performance of SMEs. The study therefore recommended that SMEs' internal and external operations and changing the structure should be continuously evaluated to ensure that there is optimal benefit to SMEs performance.
\end{abstract}

Keywords: Reorganization, Turnaround Strategy, Performance.

\section{Introduction}

According to Hoshino (2013), reorganization is a broad description of any change in the internal management of an organization. The purpose of reorganization is to support strategies of retrenchment or repositioning. It involves change in planning systems, the extent of decentralization, styles of human resources management, or organizational culture (Hoshino, 2013). Over a three-year reorganization period successful companies were found to be most likely to adopt cost and expense reduction, company size reduction and disposal of non-core assets while operational strategies aimed at reconfiguring internal operations and systems were not likely to be associated with successful companies (Evans, et al., 2013). Reduction in supply chain complexity improves delivery performance, but has no impact on inventory. Supply chain type has no impact on service level, but brands with in-house production are better in improving inventory than those with outsourced production. Non-seasonal business units improve service faster than seasonal ones, yet there is no impact on inventory (Appelqvist, et al., 2013). This means that compatibility of reorganization actions with the confirmed reorganization plan can affect positively performance (Laitinen, 2013).

Leaders can strongly influence a process of change in mindsets, practices and curricula to incorporate sustainability into higher business education institutions. Whereas bottom-up leadership initiatives are crucial, leadership support from top management is seen as important to enable larger, more radical steps of transformation - this can impact positively on performance (Lee \& Schaltegger, 2014). According to Laitinen (2008), useful data system can be developed on the basis of pre-filing non-financial information to support reorganization decision. Pre-filing financial information only marginally improves quality of information. Submission and reorganization plan information improve quality in terms of fit but do not significantly improve classification accuracy.

A comparative study by Champieux, et al., (2008), reveals two paths to conducting a reorganization of acquisitions in academic libraries, but with the same goal: doing more with less staff while promoting a more cost-efficient model of operations. Sawchuk (2001) presents a case study on union-based research and education activity generated in response to restructuring in the Canadian telecommunications industry and workplace reorganization. Findings suggest that an education/research/policy dynamic rooted in the union local helps to build the potential for workplace democracy and organizational capacity in the labour movement. Kontes (2004) believes that top management should consider redefining the activities and changing the structure of the organization to become a powerful enabler of, and not an obstacle to, superior performance. To improve the performance of the corporate organization, top management needs to address two challenging tasks: first, how to create a new model of the organization and, second, how to replace the old model of the organization.

\section{Statement Of The Problem}

Panicker and Manimala (2015) on the study of successful turnaround: the role of appropriate entrepreneurial strategies found out that the primary causes of organizational decline are the internal weaknesses of the organization which can be managed by adopting a variety of strategies. Nacheri and Ogolla (2015) in the study of influence of turnaround strategy adoption on revenue performance of Kenya Revenue Authority established that turnaround strategy employed by the organization contributed to better revenue performance. The study failed to highlight how better the revenue performance. Another important study conducted by Birir, 
et al., (2014) on the effects of turnaround strategies on performance of public corporation in Kenya focused mainly on two strategies; revenue generation and cost reduction strategies as the only turn strategies which affect performance of public corporation and went further to recommend that public corporations need to implement turnaround strategies to turnaround declining corporation. Birir, et al., (2014) study failed to highlight expeditiously the relationship between reorganization turnaround strategy and performance which the current study focused on.

\section{Literature Review}

Kontes (2004) opines that top management ought to consider redefining the activities and changing the structure of the organization to become a powerful enabler of, and not an obstacle to, superior performance. To improve the performance of the corporate organization, top management needs to address two challenging tasks by either creating a new model of the organization and/ or replacing the old model of the organization. A study done by Champieux, et al., (2008) discloses two paths of conducting a reorganization and acquisitions in academic libraries. Non-seasonal business units improve service faster than seasonal ones, yet there is no impact on inventory (Appelqvist, et al., 2013). This means that compatibility of reorganization actions with the confirmed reorganization plan can affect positively performance (Laitinen, 2013). Organizational performance can be judged by many different constituencies, resulting in many different interpretations of successful performance. Each of these perspectives of organizational performance can be argued to be unique (Carton, 2004). Performance management can take many forms from dealing with issues internal to the organization to catering to stakeholders or handling issues in its environment. Performance management involves the use of both quantitative and qualitative techniques and paying due attention to the human (behavioral) side of the enterprise (Arie, 2005).According to Afrifa and Tauringana (2015), for all SMEs, corporate governance factors - board size, chief executive officer (CEO) age and tenure, and directors' remuneration - are significantly associated with performance of SMEs. The results also suggest that while board size is associated with the performance of both small and medium enterprises, CEO age is significant only for medium firms and directors' remuneration only for small ones, while CEO tenure and proportion of non-executive directors are not significant for either. Empirical analysis from 147 Indian SMEs suggests that information system performance measurement framework can be the foundation for SMEs' strategic growth in the era of globalization (Sharma \& Bhagwat, 2006).

\section{Research Methodology}

The research designs that were used in this study were descriptive survey design and correlational research design. The research population in this study were 8,604 fast moving consumer goods SMEs. Stratified random sampling was adopted in this study. The study used both primary and secondary data. Primary data was collected directly from the respondents and used to analyze the relationships that were being examined in this study. Secondary data was used to acquire information on the performances of the small and medium enterprises. This information was obtained from previous evaluation reports carried out by the owners of the enterprises and from the books of accounts. Data for the current study was collected by administering the questionnaires to a sample of 375 respondents. Pearson's Product Moment Correlation Coefficient (r) was used in this study to analyze the linear relationship between the main predictor variables and the dependent variable.

\section{Findings}

The main objective of the study was to establish the relationship between reorganization turnaround strategy and performance of small and medium enterprises in Kenya. Percentages, mean score and standard deviation were used to summarize the findings as summarized in Table $1.56 .3 \%$ agreed that they are familiar with reorganization turnaround strategy in their business, $38 \%$ strongly agreed on their familiarity with business reorganization, $5.7 \%$ were neutral that is to say that they were not sure whether they were familiar with the reorganization turnaround strategy or not while none of the respondents neither disagreed nor strongly disagreed with this fact. With a mean score of 1.7 and standard deviation of 0.6 , the study can conclude therefore that the majority of the respondents were familiar with the strategy. On the other hand, $16.5 \%$ of the respondents strongly agreed that Varying of internal operations helps their organisations improve on the performance in the long run, $47.2 \%$ agreed on the same while $15.5 \%$ were not sure of the same. Cumulative figure of $20.8 \%$ disagreed that varying of internal operations helps their organisations improve on the performance in the long run. With the mean score of 2.4 and standard deviation of 1.1, the study can thus conclude that the majority $(63.7 \%)$ agreed that Varying of internal operations helps their organisations improve on the performance in the long run. The third item that was also analysed was whether the reconfiguration of internal and external operations helps the company to use resources wisely in the pursuit of company goals. In this case, $38.9 \%$ of the respondents agreed that reconfiguration of internal and external operations helps the company to use resources wisely in pursuit of company goals, $24.4 \%$ agreed, $36.7 \%$ neither agreed nor disagreed on the role of internal 
and external reconfiguration and none of the respondents disagreed on the same. Having scored a mean of 2.1 and a standard deviation of 0.8 , the study can indicate that the majority of the respondents $(63.3 \%)$ agreed that reconfiguration of internal and external operations helps the company to use resources wisely in the pursuit of company goals.

The fourth item on the reconfiguration turnaround strategy was that does reconfiguration of internal and external operations enables a company to present a unified front to customers, and vendors when a common marketing message is used throughout the organization. On this item however, $21.8 \%$ of the respondents strongly agreed with this fact, $34.8 \%$ agreed, $30.4 \%$ neither agreed nor disagreed, and $13 \%$ disagreed. This item of the study achieved a mean of 2.3 and standard deviation of 1.0. This result therefore indicate that the majority $(56.6 \%)$ of the respondents agreed that reconfiguration of internal and external operations enables our company to present a unified front to customers, and vendors when a common marketing message is used throughout the organization.

The fifth item was on whether the changing the structure allows the company to better focus on a single set of goals where $10.8 \%$ and $60.1 \%$ of the respondents strongly agreed and agreed respectively that changing the structure allows their own company to better focus on a single set of goals, $19 \%$ neither agreed nor disagreed, $10.1 \%$ disagreed on the same. This item sored a mean of 2.3 and 0.8 as a standard deviation. With these results, the majority of the respondents $(70.9 \%)$ agreed that changing the structure of the organization allows a company to better focus on a single set of goals. Lastly, the sixth item looked at the change of the management structure where $4.1 \%$ strongly agreed and $30.4 \%$ agreed that changing the management structure eliminates overlapping and duplication of work thus decreasing likelihood of turnarounds. $31 \%$ neither agreed nor disagreed and $34.5 \%$ cumulatively disagreed that this is the fact. With a mean of 3.0 and a standard deviation of 1.0, the study can indicate that this item is needed to be relooked into as there was a tie between those who were for the idea and those who were refuting. The descriptive statistics are shown in Table 1.

Table 1 Descriptive Statistics between Reorganization Turnaround Strategy and Firm Performance

\begin{tabular}{|c|c|c|c|c|c|c|c|}
\hline & \multicolumn{5}{|c|}{ Percentage $(\%) \mathrm{n}=316$} & \multirow[b]{2}{*}{$\underset{\Sigma}{\mathbb{E}}$} & \multirow[b]{2}{*}{ 旁 } \\
\hline & 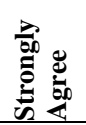 & 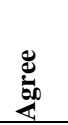 & $\underset{\bar{Z}}{\bar{Z}}$ & 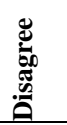 & 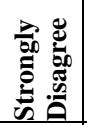 & & \\
\hline I am familiar with reorganization in our business & 38 & 56.3 & 5.7 & 0 & 0 & 1.7 & 0.6 \\
\hline $\begin{array}{l}\text { Varying of internal operations helps our organisation improve its } \\
\text { performance in the long run }\end{array}$ & 16.5 & 47.2 & 15.5 & 18 & 2.8 & 2.4 & 1.1 \\
\hline $\begin{array}{l}\text { Reconfiguration of internal and external operations helps the } \\
\text { company to use resources wisely in the pursuit of company goals }\end{array}$ & 24.4 & 38.9 & 36.7 & 0 & 0 & 2.1 & 0.8 \\
\hline $\begin{array}{l}\text { Reconfiguration of internal and external operations enables our } \\
\text { company to present a unified front to customers, and vendors when a } \\
\text { common marketing message is used throughout the organization }\end{array}$ & 21.8 & 34.8 & 30.4 & 13 & 0 & 2.3 & 1.0 \\
\hline $\begin{array}{l}\text { Changing the structure allows our company to better focus on a } \\
\text { single set of goals }\end{array}$ & 10.8 & 60.1 & 19 & 10.1 & 0 & 2.3 & 0.8 \\
\hline $\begin{array}{l}\text { Changing the management structure eliminates overlapping and } \\
\text { duplication of work thus decreasing likelihood of "turnarounds" }\end{array}$ & 4.1 & 30.4 & 31 & 27.2 & 7.3 & 3.0 & 1.0 \\
\hline
\end{tabular}

The literature that was reviewed in this study as well as theoretical reasoning associated reorganization turnaround strategy with organizational performance. Organizational performance in this case, was indicated by profitability and return on assets while reorganization turnaround strategy was indicated by reconfiguration of internal and external operation and changing the structure of the organization. Following the theoretical arguments, the following hypothesis was formulated and tested: There is no significant relationship between reorganization turnaround strategy and performance of small and medium enterprises in Kenya. The model summary in Table 2 demonstrates the coefficient of determination as indicated by $\mathrm{R}$ squared to be 0.370 implying that $37 \%$ of the SME performance is explained by reorganization turnaround strategy while the other factors explains the remaining proportion.

Table 2 Model Summary for Reorganization Turnaround Strategy and SME Performance

\begin{tabular}{|l|l|l|l|l|l|}
\hline Model & $\mathbf{R}$ & R Square & Adjusted R Square & Std. Error of the Estimate & Durbin-Watson \\
\hline 1 & $.608 \mathrm{a}$ & 0.370 & 0.362 & 0.141 & 2.069 \\
\hline a Predictors: (Constant), Reorganization & & \\
\hline
\end{tabular}

In Table 3 the ANOVA was used to show the overall model significance. Since the p-value is less than 0.05 , then reorganization restructuring turnaround strategy had a significant explanatory power on SMEs performance $(\mathrm{F}=32.839$ and $\mathrm{p}$ value $<0.05)$. 


\section{Relationship Between Reorganization Turnaround Strategy And Performance Of Small And Medium..}

Table 3 ANOVA for Reorganization Turnaround Strategy and SME Performance

\begin{tabular}{|l|l|l|l|l|l|l|}
\hline Model & Sum of Squares & df & Mean Square & F & Sig. \\
\hline 1 & Regression & 324 & 1 & 324 & 32.839 & $.000 \mathrm{~b}$ \\
\hline & Residual & 3098.009 & 314 & 9.866 & & \\
\hline \multicolumn{2}{|l|}{ Total } & 3422.009 & 315 & & & \\
\hline a Dependent Variable: Firm performance & & & \\
\hline b Predictors: (Constant), Reorganization & & \\
\hline
\end{tabular}

From Table 4, regression equation can be written as:

GTP $=4.85+1.01$ Reorganization Turnaround Strategy

There is a positive and significant relationship between reorganization turnaround strategy and SME performance in Kenya. A unit increase in reorganization strategy increases SMEs performance by 1.01 units. Since the $\mathrm{P}$ value was less than 0.05 then there is enough evidence to warrant rejection of the null hypothesis and conclusion that there is a significant relationship between SMEs performance and reorganization turnaround strategy.

Table 4Regression Coefficients for Reorganization Turnaround Strategy and SME Performance

\begin{tabular}{|l|l|l|l|l|l|l|l|l|}
\hline Model & \multicolumn{2}{|l|}{ Unstandardized Coefficients } & $\begin{array}{l}\text { Standardized } \\
\text { Coefficients }\end{array}$ & & \multicolumn{2}{l|}{ Collinearity Statistics } \\
\hline & & B & Std. Error & Beta & t & Sig. & Tolerance & VIF \\
\hline 1 & (Constant) & 4.85 & 0.177 & & 27.46 & .000 & & \\
\hline & Reorganization & 1.01 & 0.177 & 0.308 & 5.73 & .000 & 1 & 1 \\
\hline a Dependent Variable: Firm performance
\end{tabular}

The researcher studied the relationship between reorganization turnaround strategy and performance of small and medium enterprises in Kenya where null hypothesis was stated as: There is no significant relationship between reorganization turnaround strategy and performance of small and medium enterprises in Kenya. The results showed a significant and positive relationship between reorganization and performance of SMEs thus rejecting the null hypothesis. These results confirm the prepositions of the Laitien (2011) on the study of effect of reorganization actions on the financial performance of small entrepreneurial distressed firms who suggested that the more an organisations is compactible to reorganization turnaround strategies the higher the chances of the organization performing better and better.

Even so, Appelqvist, et al., (2013) on the study of the turnaround across diverse global supply chains using shared metrics and change methodology: the case of Amer Sports Corporation, noted some business especially, non-seasonal ones can improve performance faster than seasonal business. Lee \& Schaltegger, (2014) on the study of Organizational transformation and higher sustainability management education: the case of the MBA sustainability management, suggested that, for a firm to achieve transformation expected during the reorganization turnaround strategies, leaders from the top management are usually instrumental in enabling large and more radical changes tailored to improving firm performance positively. Even though a largest proportion of the participants $(52.3 \%)$ disagreed with reconfiguration of both the internal and external operations in helping to spend the organisation's resources wisely, a significant group of respondents $(36.7 \%)$ were unsure of their choice. This confirmed the findings of Evans, et al., (2013) on the study of the applications of proxy system modeling in high resolution paleoclimatology found reconfiguration of operations to have no likely effect with the success of the companies.

Harwood, et al., (2016) on the study of effects of organizational restructuring on firm performance: a Case of national bank of Kenya, explored organisation restructuring on the performance of National Bank of Kenya found that there was a positive but insignificant relationship. The bank was found to be significantly affected by staffing, which was either over or under staffed, and stagnating workforce productivity which were to blame for the failure of the bank performance. So with good management of the workforce and change of services being rendered to consumers would lower operating costs and help organisation to full implement other reorganisations turnaround strategies thereby improving the firm's performance. Kontes (2004) on the study of a new look for the corporate center: reorganizing to maximize value, believed of changing the structures for superior performance was proved to have no better focus on goals as most respondents (70.9\%) in the current study showed their disagreement in this belief according to their organisations. Also, most respondents opinionated that changing the management structure would not help eliminate overlapping and duplication of work which further indicate need to address this problem using different methods. A study in Canada telecommunications by Sawchuk (2001) on trade union-based workplace learning: a case study in workplace reorganization and worker knowledge production, suggested a union of the teams involved in reorganisation strategy that will help to build democracy at workplace as well as increase the organisation capacity. It can be concluded therefore that when reorganising, the organisation should strive to achieve the same goals with a 
reduced number of staffing that will not compromise the quality of services delivered and help to have an increased efficiency in cost of operations.

\section{Conclusion}

From the results obtained by the current study, there was positive and significant relationship between reorganization turnaround strategy and performance of SMEs. Kontes (2004) concurs with these findings on the study of a new look for the corporate center: reorganizing to maximize value, where the study believed of changing the structures for superior performance. There is need therefore to continuously reorganize the SMEs management structure. Through this reorganization there are high chances of increasing efficiency by minimizing transactional costs and saving on costs related with employee's redundancies. More so, since SMEs are mostly in growth stage different levels of growth may require changes in organization reorganization.

\section{Recommendation}

Reorganization turnaround strategy has significant contribution on SMEs performance. This implies that reorganization of internal and external operations and changing the structure should be continuously evaluated to ensure that there is optimal benefit to SMEs performance. Also revealed in the study reorganization of SMEs improves efficiency which would ultimately ensure smooth operations and consequently increase profit levels.

\section{References}

[1]. Appelqvist, P., Valérie, C., Ari-Pekka, H., Jussi, H., \& Vincent, W. (2013). Turnaround across diverse global supply chains using shared metrics and change methodology: The case of Amer Sports Corporation. International Journal of Operations \& Production Management, 33(5), 622 - 647.

[2]. Arie, H. (2005). Performance Measurement is only one way of Managing Performance, International Journal of Productivity and Performance Management, 54 (7).

[3]. Birir, L., Henry, K., \& Simon, K. (2014). Effect of turnaround strategies on performance of public corporations in Kenya Journal. International Journal of Management \& Information Technology, 10 (4).

[4]. Carton, R. (2004). Measuring Organizational Performance: an exploratory study.

[5]. Champieux, R., Jackson, M. \& Carrico, S., (2008). Implementing change and reorganization in the acquisitions departments at the University of Alabama and the University of Florida. Emerald Group Publishing Limited, 21(4), 113-121. Doi 10.1108/08880450810929080.

[6]. Champieux, R., Millie, J., and Steven, C. (2008). Implementing change and reorganization in the acquisitions departments at the University of Alabama and the University of Florida, The Bottom Line, 21(4), 113 - 121

[7]. Evans, M. N., Tolwiski, S. E., Thompson, D. M., \& Achukitis, K. J. (2013). Application proxy system modeling in high resolution paleoclimatology. Quaternary science reviews, 76, 16-28.

[8]. Harwood, I. K., Nakola, J. O. \& Nyaana, D. N., (2016). Effects of Organizational Restructuring on Firm Performance: A Case of National Bank of Kenya. Global Journal of Advanced Research, 3(1), 43-49.

[9]. Kontes, P. (2004). A new look for the corporate center: reorganizing to maximize value", Journal of Business Strategy, 25 (4), 18 24.

[10]. Laitinen, K. (2008). Data system for assessing probability of failure in SME reorganization, Industrial Management \& Data Systems, $108(7), 849-866$.

[11]. Laitinen, K. (2011). Effect of reorganization actions on the financial performance of small entrepreneurial distressed firms, Journal of Accounting \& Organizational Change 7 (1), 57 - 95

[12]. Lee, K., \& Schaltegger, S. (2014). Organizational transformation and higher sustainability management education: The case of the MBA Sustainability Management, International

[13]. Nacheri, P., \& Ogolla, K. (2015). Influence of Turnaround Strategy Adoption on Revenue Performance of Kenya Revenue Authority, Journal of Business and Management 17 (4) 84-89

[14]. Panicker, S., \& Manimala, J. (2015). Successful turnarounds: the role of appropriate entrepreneurial strategies, Journal of Strategy and Management, 8 (1), $21-40$.

[15]. Sawchuk, H. (2001). Trade union-based workplace learning: a case study in workplace reorganization and worker knowledge production, Journal of Workplace Learning, 13 (7/8), 344 - 351

[16]. Sharma, M., \& Bhagwat, R. (2006). Performance measurements in the implementation of information systems in small and medium-sized enterprises: a framework and empirical analysis, Measuring Business Excellence, 10 (4), 8 - 21. 